\title{
Tiotropium in asthma: a systematic review
}

\author{
This article was published in the following Dove Press journal: \\ Journal of Asthma and Allergy \\ 27 February 2014 \\ Number of times this article has been viewed
}

\author{
Elizabeth Befekadu' \\ Claudia Onofrei' \\ Gene L Colice ${ }^{1,2}$ \\ 'MedStar Washington Hospital Center, \\ Washington, DC, USA; ${ }^{2}$ The George \\ Washington University School \\ of Medicine and Health Sciences, \\ Washington, DC, USA
}

Correspondence: Gene L Colice Washington Hospital Center, I IO Irving St NW, Washington, DC 20010, USA

Tel +l 2028777195

$\mathrm{Fax}+\mathrm{I} 2022910386$

Email gene.colice@medstar.net
Introduction: The objective of this paper is to systematically review the existing evidence of the effectiveness and safety profile of a long-acting inhaled muscarinic antagonist as add-on therapy in patients with asthma that is uncontrolled despite inhaled corticosteroid (ICS) use.

Methods: With the assistance of two experienced research librarians, we searched Ovid MEDLINE/PubMed (1946 to September 12, 2013), the Cochrane Library review, and the TRIP database. The key search terms were "tiotropium and asthma." The search was limited to human data published in English. Included in the systematic review were all randomized controlled trials that evaluated the efficacy of tiotropium in patients with asthma. The clinical trials had to be at least 4 weeks in duration and to provide adequate information on clinically appropriate end points in asthma care (eg, change in lung function, exacerbation rates, and/or ICS dosing). Data on patient characteristics, study design, outcome measures, concomitant asthma medication, and adverse events were extracted from the full text of each included individual study. Marked heterogeneity of study design precluded statistical pooling of results for a meta-analysis. Consequently, only descriptive summaries of outcomes are provided.

Results: Our database search retrieved 149 citations. We found five randomized controlled trials in humans that met our criteria for inclusion in the systematic review. We also found two open-label uncontrolled trials that were considered in the discussion. Each of the five included studies met the Consolidated Standards of Reporting Trials criteria for a well-designed randomized trial.

Discussion: The five clinical studies included in this systematic review focused on evaluating the efficacy of tiotropium as add-on therapy to ICS or ICS in combination with a long-acting inhaled $\beta_{2}$-agonist (LABA) in patients with uncontrolled moderate to severe persistent asthma. Tiotropium maintained lung function when ICSs were tapered and when an LABA was discontinued. Tiotropium improved lung function when added to ICS alone or ICS-LABA combination therapy. In the only trial to have compared the addition of tiotropium with doubling the dose of ICS, tiotropium provided significantly superior results. In trials in which the addition of tiotropium was compared with salmeterol, the beneficial effects of these two bronchodilators were similar. No safety concerns were found with use of tiotropium as add-on therapy.

Conclusion: Tiotropium may have a beneficial role in moderate to severe persistent asthma despite use of an ICS or ICS and LABA. Use of tiotropium as add-on therapy poses no safety concerns.

Keywords: tiotropium, asthma, lung, inflammation, inhaled corticosteroid, LABA, LAMA

\section{Introduction}

Asthma is a chronic inflammatory airway disease. ${ }^{1}$ Airway inflammation in asthma is characterized by bronchial wall infiltration by eosinophils, activated mast cells, and $\mathrm{T}$ lymphocytes. Cytokines from $\mathrm{T}$ helper 2 cells and leukotrienes play key roles in mediating airway inflammation. Also seen are goblet cell hyperplasia, mucus gland hypertrophy, and airway mucus accumulation. Increased airway smooth 
muscle mass and reversible bronchoconstriction are other important features of asthma. Airway inflammation, mucus accumulation, and bronchospasm account for the symptoms of shortness of breath, wheezing, cough, and chest tightness in asthma. ${ }^{1}$ Understanding asthma pathophysiology is an important issue for health care practitioners in the US because asthma prevalence increased from $7.3 \%$ in 2001 to $8.4 \%$ in 2010. In 2010, an estimated 25.7 million Americans had asthma -18.7 million adults aged 18 years and over and 7.0 million children aged $0-17$ years. $^{2}$

The ultimate goal of asthma management is to minimize symptoms, prevent acute exacerbations, and avoid adverse medication effects. The pathophysiologic features of asthma explain why current US and international guidelines recommend the use of an inhaled corticosteroid (ICS) and a short-acting inhaled $\beta_{2}$-agonist (SABA) for treatment of persistent asthma., ${ }^{3,4}$ ICSs can control airway inflammation, 5,6 and SABAs can manage acute symptoms related to bronchospasm. To reduce the risk of drug-related side effects, current asthma management guidelines recommend a stepwise treatment approach to achieving optimal asthma control, with more aggressive ICS dosing reserved for patients with more severe disease. ${ }^{3,4}$ However, prospective studies have confirmed that a significant proportion of asthma patients do not achieve asthma control, even with maximal approved doses of ICS. ${ }^{7}$ In patients who do not respond to ICS treatment alone, asthma guidelines recommend addition of another long-term controller, such as a long-acting inhaled $\beta_{2}$-agonist (LABA), a leukotriene-modifying agent (LMA), theophylline, and/or an anti-immunoglobulin E monoclonal antibody. Despite the addition of agents like LABAs and LMAs to ICSs, many asthma patients still remain both symptomatic and obstructed. ${ }^{8}$ There is clearly a need for alternative medications with different modes of action in asthma management. One intriguing option as an add-on therapy for asthma patients not responding to ICSs is an anticholinergic.

Tiotropium bromide is a long-acting inhaled muscarinic antagonist (LAMA). It has high potency as a selective antagonist at the muscarinic acetylcholine (Ach) receptors. Tiotropium rapidly dissociates from M2 Ach receptors but slowly dissociates from M3 Ach receptors. ${ }^{9}$ Consequently, tiotropium provides 24-hour bronchodilation as maintenance therapy in moderate to severe chronic obstructive pulmonary disease (COPD). ${ }^{10,11}$ Tiotropium has also been shown to reduce goblet cell metaplasia and airway smooth muscle mass in allergen-challenged mice and guinea pigs. ${ }^{12,13}$ Early evidence of clinical benefit with LAMA therapy in asthma was identified in COPD patients with airway hyper-responsiveness and concomitant asthma. ${ }^{14-16}$

The objective of this paper is to systematically review the existing evidence of the use of tiotropium in patients with uncontrolled asthma and to provide recommendations for its potential role in the treatment of asthma. We sought to answer the question what is the existing evidence of the effectiveness and safety profile of an LAMA as add-on therapy in patients with asthma that is uncontrolled despite ICS use?

\section{Materials and methods Search strategy and study selection}

We adhered to the Preferred Reporting Items for Systematic Reviews and Meta-Analyses (PRISMA) criteria when performing this study. ${ }^{17}$ With the assistance of two experienced research librarians, we searched Ovid MEDLINE/PubMed (1946 to September 12, 2013), the Cochrane Library review, and the TRIP database. The key search terms were "tiotropium and asthma." The search was limited to human data published in English.

Abstracts of articles identified in the search were reviewed independently by two of the authors. Articles meeting preidentified inclusion and exclusion criteria were selected for evaluation in this systematic review. Disagreements about inclusion of individual articles were resolved by consensus or review by a third author. Included in the systematic review were all randomized controlled trials that evaluated the efficacy of tiotropium in patients with asthma. The clinical trials had to be at least 4 weeks in duration and to provide adequate information on clinically appropriate end points in asthma care (eg, change in lung function, exacerbation rates, and/or ICS dosing). Excluded were unpublished and ongoing research, animal studies, reviews, case reports, case series, editorials, and studies in COPD patients (with or without asthma). The references of published articles identified in the search were examined for additional studies appropriate for inclusion in the review.

\section{Data extraction and quality assessment}

Data on patient characteristics, study design, outcome measures, concomitant asthma medication, and adverse events were extracted from the full text of each included individual study. The methodologic quality of the trials was evaluated using criteria reported in the Consolidated Standards of Reporting Trials (CONSORT) Statement. ${ }^{18}$ Marked heterogeneity of study design precluded statistical pooling of results for a meta-analysis. Consequently, only descriptive summaries of outcomes are provided. 


\section{Results}

Our database search retrieved 149 citations of which 93 were excluded because they did not meet the inclusion criterion of being specific to the effect of tiotropium in asthma (Figure 1). An additional 37 citations were excluded because they did not describe results of clinical trials in humans. Twelve other citations were not included. Two were single-patient case reports, one was in Japanese, six had duplicate information, and three studies did not make a distinction between asthma and COPD.

We found five randomized controlled trials in humans that met our criteria for inclusion in the systematic review. ${ }^{19-23}$
One open-label study without a control was identified in the database search. ${ }^{24}$ This study was not included in the systematic review but was considered in the discussion. Following review of the references of the selected papers, an additional open-label trial without a control group was identified. ${ }^{25}$ This study was not included in the systematic review but was considered in the discussion. Summary descriptions of the five publications that met inclusion criteria are provided in Tables 1 and 2. Detailed descriptions of the five selected studies are provided as follows.

Fardon et $\mathrm{al}^{19}$ evaluated the ICS sparing ability of tiotropium in patients with severe persistent asthma.

Citations identified from Ovid and PubMed $(n=149)$

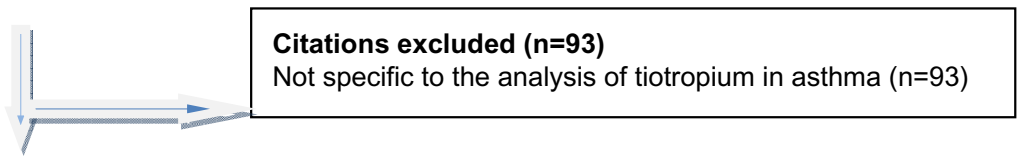

Citations specific to tiotropium in asthma $(n=56)$

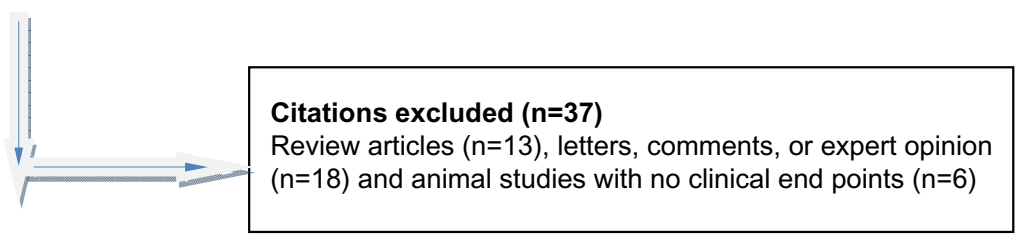

Citations describing results of tiotropium clinical experience $(n=19)$

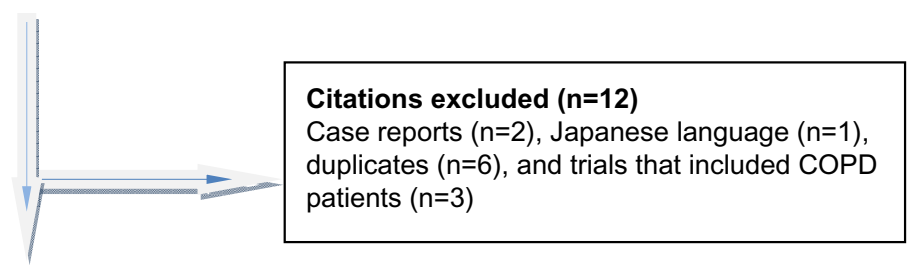

Citations describing results of controlled clinical trials with tiotropium in asthma $(n=7)$

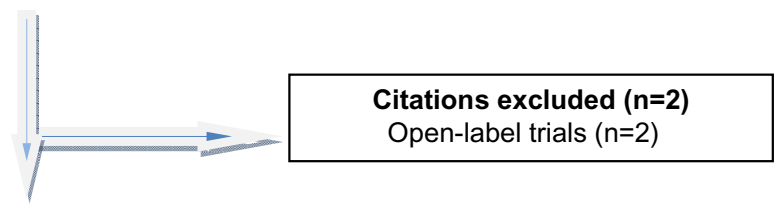

Total publications reviewed $(n=5)$

Figure I Selection process of citations.

Abbreviation: COPD, chronic obstructive pulmonary disease. 


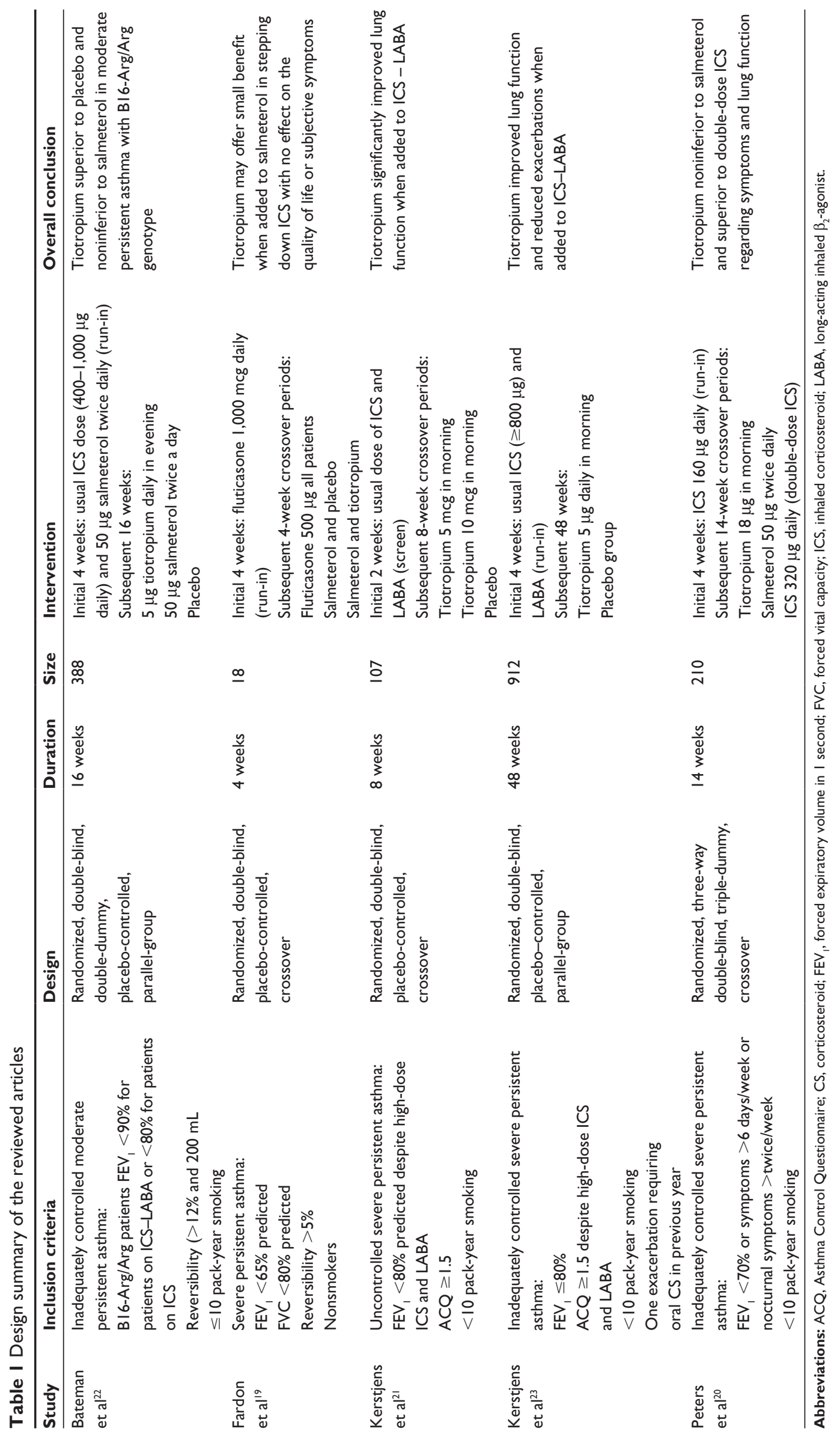




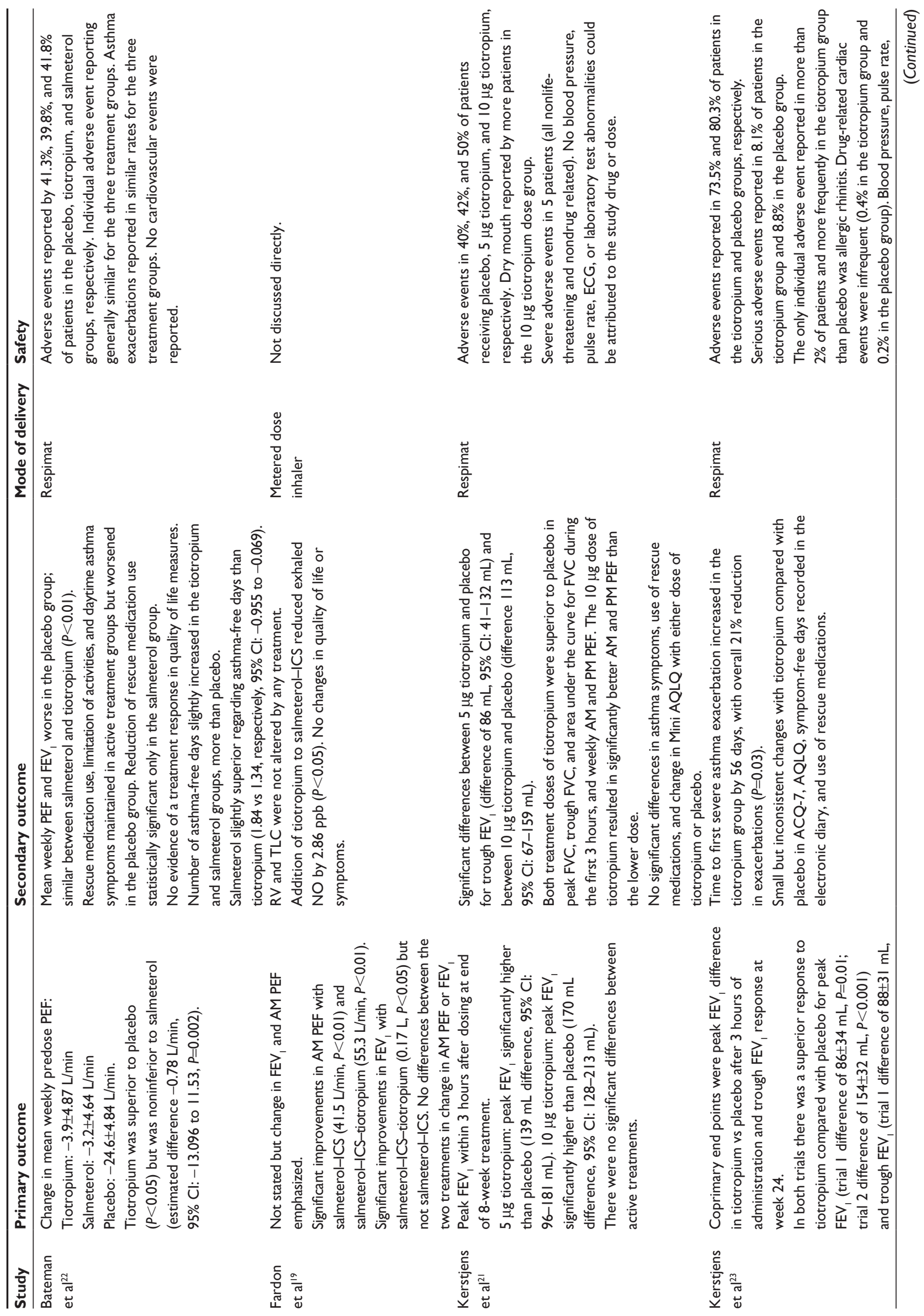




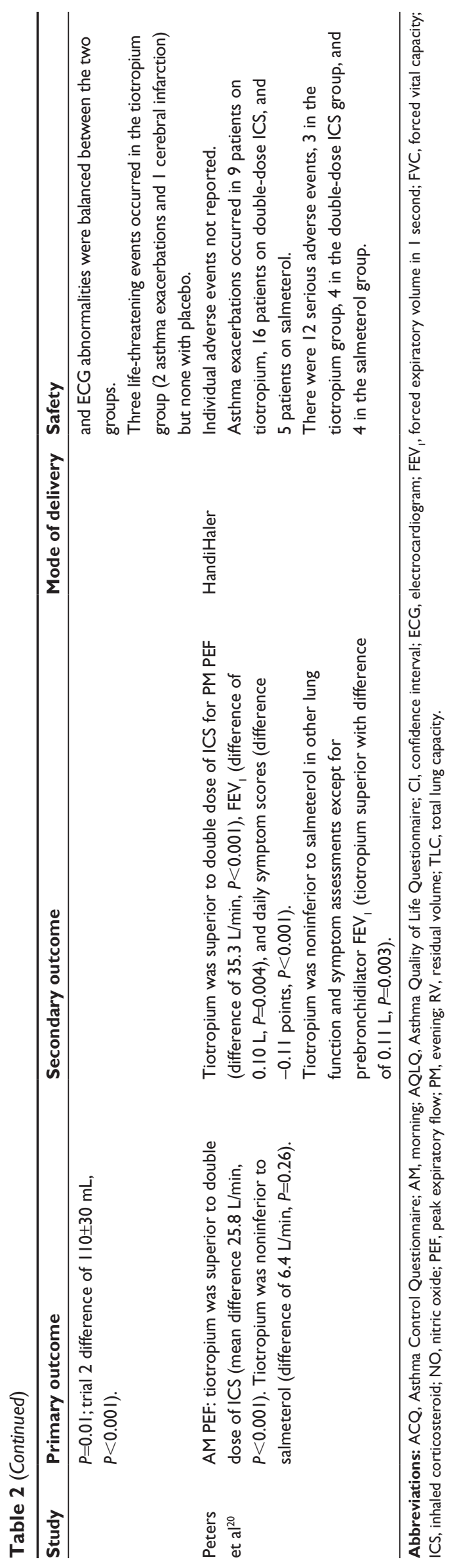

Inclusion criteria for this clinical trial required that study patients be adults with a clinically established diagnosis of asthma and with $>15 \%$ reversibility after an SABA or a short-acting inhaled muscarinic antagonist (SAMA). Inclusion criteria also required a forced expiratory volume in 1 second $\left(\mathrm{FEV}_{1}\right)$ of $\leq 65 \%$. Patients were excluded if they had had a recent exacerbation or had smoked at any time during their life. The study was a double-blind, randomized, placebo-controlled, crossover study. Patients were changed from their usual asthma medications to $1,000 \mu \mathrm{g}$ of fluticasone daily for a 4-week run-in period. Their dose of fluticasone was then halved to $500 \mu \mathrm{g} /$ day and an LABA was added (125/25 $\mu \mathrm{g}$ per puff and two puffs twice daily). At that point, patients entered a crossover phase in which they were randomized, first, to the addition of either tiotropium bromide ( $18 \mu \mathrm{g}$ administered once daily from a metered dose inhaler) or a matched placebo before, secondly, receiving the other treatment. The crossover phases lasted 4 weeks and there was no washout period between study phases. A specific primary outcome measure was not identified in this study. Twenty-six lifelong nonsmoking severe asthmatics with a mean $\mathrm{FEV}_{1}$ of $1.49 \mathrm{~L}$ (51\% predicted) entered the run-in phase, but only 18 patients completed the study. Four weeks after patients were switched from fluticasone $1,000 \mu \mathrm{g} /$ day to the lower dose of ICS with an LABA for the run-in period, there were significant increases in morning (AM) and evening (PM) peak expiratory flow (PEF). Four weeks after switching to the combination of an ICS-LABA with tiotropium there were significant improvements in $\mathrm{FEV}_{1}(0.17 \mathrm{~L} ; 95 \%$ confidence interval [CI]: 0.01-0.32; $P<0.05)$ and forced vital capacity (FVC) $(0.24 \mathrm{~L}, 95 \%$ CI: $0.05-0.43 ; P<0.05)$. The ICS-LABA-tiotropium combination also resulted in reduced exhaled nitric oxide levels by $2.86 \mathrm{ppb}$ ( $95 \%$ CI: $0.12-5.6 ; P<0.05)$. The increases in lung function with the triple combination of ICS-LABAtiotropium were not significantly different from the changes found with the ICS-LABA combination, though. Although there were small improvements in subjective symptoms of quality of life, measured by the Mini Asthma Quality of Life Questionnaire (Mini AQLQ) after both crossover phases, the changes were not significant. The small sample size and the fact that eight of the participants dropped out due to an asthma exacerbation were mentioned as possible reasons for the failure of the study to detect improvement in quality of life. The authors also evaluated acute changes in lung function after single doses of an SABA with an SAMA. There was a significant bronchodilator benefit after the inhalation of albuterol and ipratropium, but the response to short-acting inhaled bronchodilators did not predict the 
response to tiotropium. Safety information was not provided in this study.

Peters et $\mathrm{al}^{20}$ compared the benefit of tiotropium as add-on therapy to an ICS with that obtained by either adding an LABA or doubling the ICS dose in patients with uncontrolled persistent asthma. Patients were included if they were nonsmokers (less than 10 pack-years per lifetime), were aged 18 years or older, had an $\mathrm{FEV}_{1}>40 \%$ of the predicted value, and had a diagnosis of asthma confirmed by bronchodilator reversibility or bronchial hyperresponsiveness. The study was a three-way, double-blind, triple-dummy, crossover trial. Patients entered a 4-week run-in period during which they were treated with $160 \mu \mathrm{g}$ of beclomethasone daily. They were entered into the trial if they had either an $\mathrm{FEV}_{1} \leq 70 \%$ or daytime symptoms for 6 or more days per week or night-time symptoms 2 or more nights per week during the final 2 weeks of the run-in period. The three crossover periods involved adding tiotropium (18 $\mu \mathrm{g}$ every AM from a dry powder inhaler), adding salmeterol (50 $\mu \mathrm{g}$ twice daily by dry powder inhaler), or doubling the ICS to $320 \mu \mathrm{g}$ daily. Each treatment period lasted 14 weeks with a 2 -week washout phase between treatment periods. The identified primary outcome measure in this study was the AM PEF, and the primary hypothesis was that the addition of tiotropium to ICS would provide greater benefit than doubling the dose of ICS. Two hundred and ten severe asthma patients with a mean $\mathrm{FEV}_{1}$ of $2.31 \mathrm{~L}$ (71.5\% predicted) met the entry criteria and were randomized. Thirty-six participants dropped out during the treatment phase due to withdrawal of consent, loss to follow-up, drug-related adverse events, or miscellaneous reasons. The use of tiotropium resulted in a superior primary outcome compared with doubling the dose of an ICS. There was a greater improvement in the primary outcome measure AM PEF with tiotropium compared with a double dose of ICS, with a mean difference of $25.8 \mathrm{~L} / \mathrm{min}$ $(P<0.001)$. Tiotropium also showed superiority in most secondary outcomes. PM PEF was larger, with a difference of $35.5 \mathrm{~L} / \mathrm{min}(P<0.001)$; the proportion of asthma control days was greater, with a difference of $0.079(P=0.01)$; the $\mathrm{FEV}_{1}$ before bronchodilation was larger, with a difference of $0.10 \mathrm{~L}(P=0.004)$; and daily asthma symptom scores were lower, with a difference of -0.11 points $(P<0.001)$. In the secondary outcome analysis, addition of tiotropium to an ICS was found to be noninferior to salmeterol, as measured by the AM PEF. Although the prebronchodilator and postbronchodilator $\mathrm{FEV}_{1}$ responses favored tiotropium, tiotropium was noninferior to salmeterol in other results, including PM PEF, asthma daily symptom scores, and sputum eosinophils. Interestingly, a small $\mathrm{FEV}_{1}$ decrease in patients receiving albuterol in addition to the standing dose of salmeterol suggested a tachyphylaxis effect for $\beta$-agonists that was not found in the tiotropium group. Not increasing the dose of ICS by more than a factor of two was proposed as a potential weakness of the trial, together with the short study duration (14 weeks) and the small sample size. Although long-term safety issues were not assessed in this trial, numerically more asthma exacerbations occurred during the double-dose ICS treatment period than during the tiotropium treatment period ( $n=16$ versus [vs] $n=9)$, with the fewest occurring with salmeterol treatment $(n=5)$.

Kerstjens et $\mathrm{al}^{21}$ sought to compare the efficacy and safety of different doses of tiotropium in the Respimat ${ }^{\mathbb{B}}$ inhaler (Boehringer Ingelheim Pharma $\mathrm{GmbH}$ and $\mathrm{Co}, \mathrm{KG}$, Ingelheim, Germany) against placebo as add-on therapy in patients with uncontrolled severe persistent asthma. Patients included in this trial were aged 18 years and older and had at least a 5-year history of asthma. They were required to have a postbronchodilator $\mathrm{FEV}_{1} \leq 80 \%$ and to have an Asthma Control Questionnaire (ACQ) score of $\geq 1.5$ despite treatment with high-dose ICS and an LABA. Interestingly, patients were allowed to remain on a stable dose of theophylline, LMA, and oral corticosteroid throughout the study. Patients were excluded if they had a smoking history of $\geq 10$ pack-years or a diagnosis of COPD. The authors conducted a randomized, double-blind, crossover study with three 8-week treatment periods. After a 2 -week run-in period, eligible patients were randomized to receive each of three treatments in a random sequence for 8 weeks in a crossover design $(5 \mu \mathrm{g}$ or $10 \mu \mathrm{g}$ of tiotropium or matching placebo administered as two actuations once daily in the AM from the Respimat inhaler). There was no washout phase between treatment periods. Throughout the 24-week treatment period, participants recorded PEF and $\mathrm{FEV}_{1}$ values twice daily at home using the Asthma Monitor $\mathrm{AM} 2+$ and responded to daily questions in the electronic diary component of this device. The primary end point was peak $\mathrm{FEV}_{1}$ (obtained within 3 hours of dosing) at the end of each treatment period. Of the 107 randomized patients,

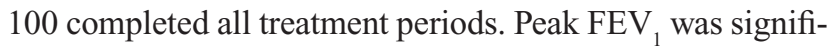
cantly higher with $5 \mu \mathrm{g}$ of tiotropium (difference $139 \mathrm{~mL}$; 95\% CI: 96-181 mL) and $10 \mu \mathrm{g}$ (difference $170 \mathrm{~mL} ; 95 \%$ CI: $128-213 \mathrm{~mL}$ ) than with placebo (both $P<0.0001$ ). Trough $\mathrm{FEV}_{1}$ at the end of the dosing interval was also higher with both doses of tiotropium than with placebo (difference with $5 \mu \mathrm{g}$ of $86 \mathrm{~mL}$ [95\% CI: 41-132]; difference with $10 \mu \mathrm{g}$ of $113 \mathrm{~mL}$ [95\% CI: 67-159 mL], both $P<0.0004)$. Although there were numerically greater $\mathrm{FEV}_{1}$ responses with the $10 \mu \mathrm{g}$ dose of tiotropium than with the $5 \mu \mathrm{g}$ dose compared with placebo 
for both peak and trough $\mathrm{FEV}_{1}$, the differences in outcome measures between the two active doses were not significant. Across groups, no significant difference was noted in asthmarelated health status, rescue medication use, or symptoms measured in the electronic diary. There was a trend for more adverse events to be reported with the $10 \mu \mathrm{g}$ tiotropium treatment group than with the placebo group. Patients receiving the highest dose of tiotropium specifically reported more complaints about dry mouth than the placebo group $(6.8 \%$ vs $1.0 \%$ ). Serious adverse events and asthma exacerbations were few and balanced among the treatment groups.

Bateman et $\mathrm{al}^{22}$ compared the efficacy and safety of tiotropium as add-on therapy to patients with moderate persistent asthma not adequately controlled by ICS therapy alone against salmeterol and placebo. As a novel twist of this study, the authors focused their study on a specific group of asthma patients with the B16-Arg/Arg genotype. Patients with a history of asthma with the B16-Arg/Arg genotype and receiving maintenance therapy with ICS of 400-1,000 $\mu \mathrm{g} /$ day of budesonide or equivalent were eligible for enrollment. The main inclusion criteria were reversible airway obstruction (improvement in $\mathrm{FEV}_{1}$ of at least $12 \%$ and $200 \mathrm{~mL}$ after sequential inhalation of $80 \mu \mathrm{g}$ of ipratropium bromide and $400 \mu \mathrm{g}$ of salbutamol) and prebronchodilator $\mathrm{FEV}_{1}$ of $90 \%$ of predicted value or less for patients previously receiving a daily dose of at least $100 \mu \mathrm{g}$ of salmeterol or $18 \mu \mathrm{g}$ of formoterol and an ICS of $80 \%$ of predicted value or less for patients previously receiving ICSs only. The main exclusion criteria were smoking history ( $>10$ pack-years), COPD, serious concomitant illnesses, and concomitant respiratory medications. They conducted a double-blind, double-dummy, placebocontrolled, parallel-group trial. There was a 4-week run-in period during which patients received $50 \mu \mathrm{g}$ of twice-daily salmeterol administered through a metered dose inhaler along with their ICS. After the run-in period, patients were randomized to 16 weeks of treatment with tiotropium (two puffs of $2.5 \mu \mathrm{g}$ daily in the PM through the Respimat inhaler), salmeterol metered dose inhaler (two puffs of $25 \mu \mathrm{g}$ twice daily plus tiotropium-matching placebo), or placebo (with both a tiotropium and salmeterol matching placebo). The primary end point was change in weekly AM (predose) PEF from the last week of run-in period to the last week of treatment. A total of 530 patients were eligible for the trial and 388 were randomized. At baseline almost all patients were receiving ICSs. The majority of patients in each treatment group were also receiving an LABA. The prebronchodilator $\mathrm{FEV}_{1}$ was between $68 \%$ and $70 \%$ for the three treatment groups. There was, on average, between a $24 \%$ and $28 \%$ increase in $\mathrm{FEV}_{1}$ after ipratropium and albuterol. The AM PEF was maintained with tiotropium $(-3.9 \pm 4.87 \mathrm{~L} / \mathrm{min}$ change from run-in) and salmeterol $(-3.2 \pm 4.64 \mathrm{~L} / \mathrm{min}$ change from run-in), but the AM PEF decreased with placebo $(-24.6 \pm 4.84 \mathrm{~L} / \mathrm{min}$ from run-in). Both active treatments provided significantly superior effects on AM PEF compared with placebo. The tiotropium effect was noninferior to salmeterol. Weekly FEV measures showed the same treatment effects as the AM PEF. Surprisingly, little evidence of treatment effect with tiotropium and salmeterol was found in asthma symptoms, rescue medication use, and the Mini AQLQ. In general, adverse event reporting was comparable across treatment groups. There were numerically more asthma exacerbations with salmeterol treatment $(n=4)$ than with either placebo $(n=1)$ or tiotropium $(n=0)$.

In two large replicate studies, Kerstjens et $\mathrm{al}^{23}$ compared the effect of adding $5 \mu \mathrm{g}$ of tiotropium each AM to placebo on lung function and exacerbations in poorly controlled asthma patients already receiving ICS and LABA. Included patients were aged between 18 years and 75 years and had a 5-year or longer asthma history. Other inclusion criteria consisted of an ACQ score of 1.5 or higher, a postbronchodilator $\mathrm{FEV}_{1} \leq 80 \%$ predicted, and a postbronchodilator $\mathrm{FVC} \leq 70 \%$ predicted despite daily therapy with high-dose ICS and LABA. Included patients also had at least one asthma exacerbation in the preceding year that required treatment with systemic corticosteroids. Main exclusion criteria consisted of a pre-existent diagnosis of COPD, serious coexisting illness, and concurrent use of anticholinergic bronchodilators. Patients with a $\geq 10$ pack-years smoking history and who had smoked within the past year were also excluded. The study was a randomized, double-blind, placebo-controlled, parallel-group design. After a 4-week screening period, patients were randomized to treatment with either tiotropium ( $5 \mu \mathrm{g}$ daily) or placebo, both administered by the Respimat Soft Mist Inhaler in the AM for 48 weeks, which made it the longest trial carried out on this subject. The primary outcomes were the peak $\mathrm{FEV}_{1}$ (measured within 3 hours of treatment) and trough $\mathrm{FEV}_{1}$ at week 24 expressed as change from baseline. In the two studies, 912 eligible patients were randomized. At 24 weeks, the mean change in the peak $\mathrm{FEV}_{1}$ from baseline was greater with tiotropium than with placebo in the two trials: a difference of $86 \pm 34 \mathrm{~mL}$ in trial $1(P=0.01)$ and $154 \pm 32 \mathrm{~mL}$ in trial $2(P<0.001)$. Similar significant differences in favor of tiotropium treatment were found with the trough $\mathrm{FEV}_{1}$. The effects of tiotropium continued throughout the entire 48 weeks of the study. In addition, the addition of tiotropium increased the time to the first severe 
exacerbation (282 days vs 226 days) with an overall reduction of $21 \%$ in the risk of a severe exacerbation (hazard ratio $0.79 ; P=0.03$ ). Consistent differences between tiotropium and placebo treatment on the ACQ, the AQLQ symptom-free days, and rescue medication use were not found, however. Adverse event reporting was slightly lower with tiotropium than with placebo. No differences were found between the groups in cardiac adverse events and serious adverse events. Treatment with tiotropium was associated with a slightly higher complaint rate of dry mouth.

We performed an assessment of the methodologic quality of the five studies, and we assessed the consistency and adherence of the five trials to the CONSORT. We concluded that each study met the CONSORT criteria for a well-designed randomized trial. ${ }^{18}$

\section{Discussion}

Tiotropium is an inhaled long-acting anticholinergic currently approved in the US for once-daily maintenance treatment of bronchospasm associated with COPD. ${ }^{26}$ It has been proven to be an effective bronchodilator and to reduce the frequency of COPD exacerbations. ${ }^{10,11}$ Despite the well-studied pharmacology of tiotropium, its role in asthma remains unproven. The drug is currently not approved for non-COPD obstructive airway disease. In this systematic review we found that adding tiotropium to pre-existing therapy with only an ICS or an ICS-LABA combination resulted in significant improvements in lung function. There was also evidence from one study suggesting a reduction in exacerbations in patients with uncontrolled severe asthma. These observations are supported by findings in open-label, uncontrolled studies. The findings are consistent with the known effect of a muscarinic antagonist and its mechanism of action in the context of asthma pathophysiology.

The five clinical studies included in this systematic review focused on evaluating the efficacy of tiotropium as add-on therapy to ICS or ICS in combination with an LABA in patients with uncontrolled moderate to severe persistent asthma. Tiotropium maintained lung function when ICSs were tapered and when an LABA was discontinued. ${ }^{19,22}$ Tiotropium improved lung function when added to an ICS alone or an ICS-LABA combination therapy. ${ }^{20-23}$ In the only trial to have compared the addition of tiotropium with doubling the dose of ICS, tiotropium provided significantly superior results. ${ }^{20}$ In trials in which the addition of tiotropium was compared with salmeterol, the beneficial effects of these two bronchodilators was similar. ${ }^{20,22}$ Although the improvements in lung function appeared to be clinically meaningful, these clinical trials failed to show that tiotropium provided consistent and clinically relevant improvements in respiratory symptoms, rescue medication use, or quality of life. Perhaps the failure to show symptomatic improvements was a function of study size. In the one report powered sufficiently to assess any change in the symptomatic burden of asthma, the addition of tiotropium resulted in an overall reduction of exacerbations and an increase in the time between them. ${ }^{23}$ Overall, the consistent improvement in lung function with the addition of tiotropium should probably lead to US Food and Drug Administration approval of tiotropium as add-on therapy for patients with uncontrolled moderate to severe persistent asthma already on ICSs. Unfortunately, the available information does not enable health care providers to determine whether an individual patient might respond more to tiotropium or an LABA as add-on therapy. ${ }^{27}$

Although excluded from the systematic review, the two open-label trials we found on this topic support the findings of the other five studies. Iwamoto et $\mathrm{al}^{24}$ added tiotropium to 17 patients with severe persistent asthma who were receiving high-dose ICSs. Many of these patients were also taking an LABA and/or oral corticosteroids. The study was an openlabel, uncontrolled design. They found that use of tiotropium for 4 weeks significantly improved $\operatorname{FEV}_{1}(P=0.001)$. Of note, the percentage of eosinophils in the induced sputum of the participants was inversely correlated with the change in $\mathrm{FEV}_{1}$, whereas the neutrophil proportion was directly correlated with an increase in $\mathrm{FEV}_{1}$. This suggested that the noneosinophilic sputum profile may separate responders vs nonresponders to tiotropium therapy. A similar interest in distinguishing responders from nonresponders was reflected in the study conducted by Park et al. ${ }^{25}$ They studied 138 patients with severe persistent asthma who had reduced lung function despite high-dose ICSs and LABA. Tiotropium, administered as $18 \mu \mathrm{g}$ daily from a dry powder inhaler, was added to this regimen. Lung function tests were evaluated every 4 weeks for a minimum of 12 weeks. Responders were defined as having a $>15 \%$ (or $>200 \mathrm{~mL}$ ) improvement in $\mathrm{FEV}_{1}$, with a sustained effect lasting at least 8 successive weeks. Forty-six of the 138 patients $(33.3 \%)$ responded to tiotropium treatment. Logistic regression analysis (controlled for age, sex, and smoking status) showed that Arg16Gly in ADRB2 ( $P=0.003$, odds ratio $0.21,95 \%$ CI: $0.07-0.59)$ in a minor allele-dominant model was significantly associated with the response to tiotropium.

Improved lung function (increased $\mathrm{FEV}_{1}$ and $\mathrm{PEF}$ ) in asthma with tiotropium can be explained by its mechanism of action in the context of asthma pathophysiology. The major bronchi (the site of bronchoconstriction in asthma) have the 
densest population of cholinergic nerves in the respiratory tract. Bronchoconstriction is mainly mediated through cholinergic mechanisms in humans. ${ }^{27}$ Stimulation of cholinergic fibers leads to activation of M3 Ach receptors in the airway smooth muscle, which, in turn, causes bronchoconstriction and mucus secretion. Tiotropium is an effective M3 Ach receptor antagonist. Cholinergic stimulation may also have influences in addition to controlling airway smooth muscle contraction. Cholinergic pathways influence mucus secretion and possibly airway inflammation. It has been speculated that tiotropium might be able to affect airway remodeling in asthma through these mechanisms..$^{28,29}$

Only four of the clinical trials reported complete information on adverse events related to tiotropium use. In general, similar total and individual reporting of adverse events was described for tiotropium and salmeterol compared with placebo. The only exception was that patients receiving higher doses of tiotropium (eg, $10 \mu \mathrm{g}$ ) tended to report dry mouth more frequently. ${ }^{21}$ The cardiovascular safety profile of tiotropium is of particular interest. In COPD patients, Verhamme et $\mathrm{al}^{30}$ found that tiotropium administered $5 \mu \mathrm{g}$ daily by the Respimat Soft Mist Inhaler was associated with about a $30 \%$ increase in mortality compared with a comparable dose of tiotropium administered by a dry powder inhaler. The mortality association was strongest for cardiovascular and cerebrovascular death. However, it remains unclear whether this association is causal or due to residual confounding by COPD severity. A more recent study, also performed in COPD patients, found that tiotropium administered by the Respimat Soft Mist Inhaler at a dose of $5 \mu \mathrm{g}$ or $2.5 \mu \mathrm{g}$ had a safety profile similar to that of tiotropium given by dry powder inhaler at a dose of $18 \mu \mathrm{g} .{ }^{31}$ The 48 -week studies reported by Kerstjens et $\mathrm{a}^{23}$ described no deaths and few cardiovascular safety events in asthma patients using tiotropium administered by the Respimat Soft Mist Inhaler.

There are strengths and limitations to this systematic review. Although the number of studies included was small, the studies were of high quality. They were randomized and controlled. All studies met the CONSORT criteria for reporting of randomized trials. There were limitations, though, in the five studies. One study was small, with only 18 completed patients. ${ }^{19}$ Two studies were short, only 4 and 8 weeks. ${ }^{19,21}$ Consequently, information available regarding sustainability of benefit is somewhat limited. ${ }^{23}$ The trials were a mixture of crossover and parallel-group design, making integration of efficacy results impractical. There may still be unresolved issues regarding the appropriate dosing of tiotropium in the treatment of asthma. Different inhalation devices (with different doses) were used to administer tiotropium, metered dose inhaler, ${ }^{19}$ dry powder inhaler, ${ }^{20}$ and the Respimat Soft Mist Inhaler. ${ }^{21-23}$ One study compared the effect of $5 \mu \mathrm{g}$ of tiotropium from the Respimat vs $10 \mu \mathrm{g}$. The effects on lung function of the $10 \mu \mathrm{g}$ tiotropium dose tended to be greater, but there was also a higher reporting rate of dry mouth with the larger dose. It is unclear whether the $10 \mu \mathrm{g}$ tiotropium dose might provide additional benefits with long-term use, such as a further reduction in exacerbation rates. Although two of the studies using tiotropium in the Respimat had patients self-administer their dose in the AM, one of the studies required PM dosing. ${ }^{21-23} \mathrm{It}$ is difficult to determine from these studies whether there might be greater benefits of PM vs AM dosing.

There was limited information available from these studies regarding the anti-inflammatory benefits of tiotropium in uncontrolled asthma. Fardon et $\mathrm{a}^{19}$ found that addition of tiotropium was associated with a significant reduction in exhaled nitric oxide levels, but Peters et $\mathrm{al}^{32}$ found that immunoglobulin E levels, sputum eosinophil counts, and exhaled nitric oxide levels were not predictive of a clinical response to tiotropium. Similarly, reversibility testing to either an SABA or an SAMA was not helpful in identifying patients who would have a beneficial tiotropium response. ${ }^{19}$ Because all studies required SABA reversibility as an inclusion criterion, it is unclear whether an uncontrolled asthma patient with moderate to severe persistent disease but without reversibility would have a beneficial response to tiotropium.

In summary, there may be a beneficial role for tiotropium in moderate to severe persistent asthma patients who are uncontrolled despite use of an ICS or an ICS and an LABA. However, it remains to be determined whether the spirometric changes will ultimately reciprocate in long-term symptom improvement. The currently available literature lays a sound foundation for further studies to be designed with particular focus on the asthma population. An important issue will be to determine whether patterns of genotypes, physiology, or inflammatory markers can be identified that would identify patients with the maximal potential benefit from treatment with tiotropium in addition to currently approved therapy.

\section{Disclosure}

Drs Befekadu and Onofrei report no conflicts of interest in this work. Dr Colice is a consultant/advisory board member/ speaker for Teva, MedImmune, Pearl, Dey, Mylan, Forest, and Alitair, which are pharmaceutical companies developing treatments for asthma and COPD. 


\section{References}

1. Fanta CH. Asthma. N Eng J Med. 2009;360:1002-1014.

2. Akinbami LJ, Moorman JE, Bailey C, et al. Trends in Asthma Prevalence, Health Care Use, and Mortality in the United States, 2001-2010. Available from: http://www.cdc.gov/nchs/data/databriefs/ db94.htm. Accessed January 16, 2014.

3. National Asthma Education and Prevention Program. Expert Panel Report III. Guidelines for the Diagnosis and Management of Asthma (EPR-3). Bethesda, MD: National Heart, Lung, and Blood Institute 2007. NIH publication No 08-4051. Available from: http://www.nhlbi. nih.gov/guidelines/asthma/. Accessed January 16, 2014.

4. Global Initiative for Asthma. Global Strategy for Asthma Management and Prevention. Update 2012. Available from: http://www.ginasthma. org/documents/4. Accessed January 16, 2014.

5. Olivieri D, Chetta A, Del Donno M, et al. Effect of short-term treatment with low-dose inhaled fluticasone propionate on airway inflammation and remodeling in mild asthma. Am J Respir Crit Care Med. 1997;155: 1864-1871.

6. Trigg CJ, Manolitsas ND, Wang J, et al. Placebo-controlled immunopathologic study of four months of inhaled corticosteroids in asthma. Am J Respir Crit Care Med. 1994;150:17-22.

7. Bateman ED, Boushey HA, Bousquet J, et al. Can guideline-defined asthma control be achieved? Am J Resp Crit Care Med. 2004;170: 836-844

8. Price D, Musgrave SD, Shepstone L, et al. Leukotriene antagonists as first-line or add-on asthma-controller therapy. NEngl J Med. 2011;364: 1695-1707.

9. Scullion JE. The development of anticholinergics in the management of COPD. Int J COPD. 2007;2:33-40.

10. Tashkin DP, Celli B, Senn S, et al. A 4-year trial of tiotropium in chronic obstructive pulmonary disease. $N$ Engl J Med. 2008;359:1543-1554.

11. Vogelmeier C, Hederer B, Glaab T, et al. Tiotropium versus salmeterol for the prevention of exacerbations of COPD. NEngl J Med. 2011;364: 1093-1103.

12. Gosens R, Bos IS, Zaagsma J, Meurs H. Protective effects of tiotropium bromide in the progression of airway smooth muscle remodeling. Am J Respir Crit Care Med. 2005;171:1096-1102.

13. Kang JY, Rhee CK, Kim JS, et al. Effect of tiotropium bromide on airway remodeling in a chronic asthma model. Ann Allergy Asthma Immunol. 2012;109:29-35.

14. Terzano C, Petroianni A, Ricci A, et al. Early protective effects of tiotropium bromide in patients with airways hyperresponsiveness. Eur Rev Med Pharmacol Sci. 2004;8:259-264.

15. Magnussen H, Bugnas B, van Noord J, et al. Improvements with tiotropium in COPD patients with concomitant asthma. Respir Med. 2008;102:50-56.

16. Yoshida M, Nakano T, Fukuyama S, et al. Effects of tiotropium on lung function in severe asthmatics with or without emphysematous changes. Pulm Pharmacol Ther. 2013;26:159-166.
17. Moher D, Liberati A, Tetzlaff J, et al. Preferred reporting items for systematic reviews and meta-analyses: the PRISMA Statement. Ann Intern Med. 2009;151:264-269.

18. Schulz KF, Altman DG, Moher D, et al. CONSORT 2010 Statement: updated guidelines for reporting parallel group randomized trials. Ann Intern Med. 2010;152:726-732.

19. Fardon T, Haggart K, Lee DK, Lipworth BJ. A proof of concept study to evaluate stepping down the dose of fluticasone in combination with salmeterol and tiotripium in severe persistent asthma. Respir Med. 2007;101:1218-1228.

20. Peters SP, Kunselman SJ, Icitovic N, et al. Tiotropium bromide stepup therapy for adults with uncontrolled asthma. NEMJ. 2010;363: 1715-1726.

21. Kerstjens HAM, Disse B, Schroder-Babo W, et al. Tiotropium improves lung function in patients with severe uncontrolled asthma: a randomized controlled trial. J Allergy Clin Immunol. 2011;128:308-314.

22. Bateman ED, Kornamann O, Schmidt $P$, et al. Tiotropium is noninferior to salmeterol in maintaining improved lung function in B16-Arg/Arg patients with asthma. J Allergy Clin Immunol. 2011;128:315-322.

23. Kerstjens HA, Engle M, Dahl R, et al. Tiotropium in asthma poorly controlled with standard combination therapy. NEMJ. 2012;367: 1257-1259.

24. Iwamoto H, Yokoyama A, Shiota N, et al. Tiotropium bromide is effective for severe asthma with noneosinophilic phenotype. Eur Respir J. 2008;31:1379-1382.

25. Park HW, Yang MS, Park CS, et al. Additive role of tiotropium in severe asthmatics and Arg16Gly in ADRB2 as a potential marker to predict response. Allergy. 2009;64:778-783.

26. Product information. Spiriva (tiotropium), Ridgefield. CT: Boehringer Ingleheim Pharmacetuticals, Inc., Mar 2012.

27. Verner HA. Status asthmaticus in children: a review. Chest. 2001;119: 1913-1929.

28. Gosens R, Zaagsma J, Meurs H, Halayko AJ. Muscarinic receptor signaling in the pathophysiology of asthma and COPD. Respir Res. 2006;7:73.

29. Bateman ED, Rennard S, Barnes PJ, et al. Alternative mechanisms for tiotropium. Pulm Pharmacol Ther. 2009;22:533-542.

30. Verhamme KM, Afonso A, Romio S, et al. Use of tiotropium Respimat Soft Mist Inhaler versus HandiHaler and mortality in patients with COPD. Eur Respir J. 2013;42:606-615.

31. Wise R, Anzueto A, Cotton D, et al. Tiotropium Respimat inhaler and the risk of death in COPD. N Engl J Med. 2013;369:1491-1501.

32. Peters SP, Bleecker ER, Kunselman SJ, et al. Predictors of response to tiotropium versus salmeterol in asthmatic adults. J Allergy Clin Immunol. 2013;132:1068-1074.

Journal of Asthma and Allergy

\section{Publish your work in this journal}

The Journal of Asthma and Allergy is an international, peer-reviewed open-access journal publishing original research, reports, editorials and commentaries on the following topics: Asthma; Pulmonary physiology; Asthma related clinical health; Clinical immunology and the immunological basis of disease; Pharmacological interventions and

new therapies. Issues of patient safety and quality of care will also be considered. The manuscript management system is completely online and includes a very quick and fair peer-review system, which is all easy to use. Visit http://www.dovepress.com/testimonials.php to read real quotes from published authors.

Submit your manuscript here: http://www.dovepress.com/journal-of-asthma-and-allergy-journal 